\title{
VIRTUAL CASE STUDIES IN THE NOVEL RESOURCE DMU E-PARASITOLOGY
}

\author{
A. Peña-Fernández ${ }^{1}$, M.A. Peña ${ }^{2}$, N. Potiwat ${ }^{1}$, J. Coope ${ }^{3}$, A. Magnet ${ }^{4}$ \\ ${ }^{1}$ De Montfort University, Faculty of Health and Life Sciences (UNITED KINGDOM) \\ ${ }^{2}$ Universidad de Alcalá, Departamento de Ciencias Biomédicas (SPAIN) \\ ${ }^{3}$ De Montfort University, Postgraduate and CPD Office, Faculty of Health and Life Sciences \\ (UNITED KINGDOM) \\ ${ }^{4}$ Universidad San Pablo CEU, Facultad de Farmacia (SPAIN)
}

\begin{abstract}
A novel on-line package for teaching and learning human parasitology, named DMU e-Parasitology, is being co-developed by academics from De Montfort University (DMU, Leicester, UK) and the Spanish universities: University of San Pablo CEU and Miguel Hernández University, in conjunction with practicing Biomedical Scientists from the UK National Health Service. The DMU e-Parasitology [1] package will be freely available on the DMU website (http://parasitology.dmu.ac.uk/) late in 2018 and content/sections currently covered: a theoretical unit for the study of eukaryotic parasites that represent serious human health threats; a virtual laboratory and microscope sections for the study of these major diseases. However, for promoting active learning and increasing engagement, we are in the process of developing a fourth section with a series of virtual case studies in medical parasitology, in which students will need to reflect and critically think to reach diagnoses, propose additional diagnostic techniques and appropriate treatment. The virtual case studies will be created following a preliminary study performed by our group [2,3], in which we observed that the introduction of minicase studies in Medical Microbiology lectures [BSc Biomedical Science (BMS), DMU] last academic course were shown to be effective in facilitating the acquisition of transversal competences including clinical skills. These mini-case studies were based on those developed by the Laboratory Identification of Parasitic Diseases (DPDx) of the Centers for Disease Control and Prevention (CDC, USA) [4] and final year BMS students enrolled in this module were able to complete the case studies during the different lectures in a very short period of time. Contrarily, the virtual case studies for the DMU eParasitology will be highly interactive and students will need to use the different resources of this package, including the virtual microscope, to resolve them. Moreover, these case studies will be longer and will present different questions that the user will be able to answer depending on their clinical and parasitology skills. Between the many advantages of a virtual microscope described in the literature, including remote access to slides of high clinical quality for all users, this technological resource could facilitate the acquisition of problem-solving skills and hence the rationale of using it to resolve the case studies of the DMU e-Parasitology. This paper describes the first virtual case study created, which is available at: http://parasitology.dmu.ac.uk/learn/case_studies/cs1/story_htm/5.html [5]. Briefly: students are presented with a short medical history of an HIV positive male university student severely affected by bloody diarrhoea, malaise and fever; and a series of clinical slides in which trophozoites of Entamoeba histolytica and Acanthamoeba spp. can be observed. The "amoebas" virtual case study is student-friendly; so students can navigate through the case study following a series of questions with different degrees of difficulty related to these human pathogens. Students enrolled in the Medical Microbiology module in 2017/18 ( $n=193)$ have answered the amoebas case study during small workshops delivered to groups of 27/28 students during November 2017. Comprehensive student feedback is being collected to improve this case study, as it will be used as a model to complete this section of the DMU e-Parasitology.
\end{abstract}

Keywords: DMU-eParasitology, medical parasitology training, reflection, critical thinking, virtual case studies.

\section{INTRODUCTION}

Recent and serious outbreaks due to eukaryotic parasites in the European Union (EU) and in the United Kingdom (UK) have highlighted the relevance of the study of parasitology to develop professionals in the health sector. Thus, current health professionals should have specialised knowledge and skills to face global public health threats such as food-, water- or vector-borne parasitic diseases outbreaks. However, studies about the status of the study of parasitology in the EU have 
described a decrease of parasitology departments and the time dedicated to the study of this discipline [6]. A similar trend in the reduction of importance of teaching human parasitology has been described in China [7] and in the United States [8], regardless of current outbreaks and the increasing number of food-borne parasitic infections.

In England, and particularly in De Montfort University (DMU, Leicester, UK), the current time dedicated to the teaching of parasitology in all taught health sciences degrees is minimal or non-existent, depending on the degree programme. Thus, the study of parasites is covered on only three programmes and in differing detail in a few modules: BSc Biomedical Science [in two modules, Basic Microbiology (1st year) and Medical Microbiology (3rd year)]; MPharm Pharmacy [in three modules: Fundamental Cell Biology and Physiology (1st year); Inflammation, Cancer and Infection (3rd year) and Travel Medicine (Elective Module; 4th year)]; and finally in the BSc Pharmaceutical and Cosmetics Science [Basic Microbiology (1st year) and Applied Microbiology (Elective Module; 3rd year)].

Our teaching innovation group considers that introducing and increasing the number of lecture hours of human parasitology in human health science degrees is critical owing to the facts described above including the appearance of, and increasing infections by, emerging and re-emerging parasites [7,910]. Thus, we are undertaking a series of approaches to enhance and promote the teaching of parasitology at DMU, including curriculum changes and the development of an on-line package for teaching and studying human parasitology. In relation to the first approach, we have recently increased the number of hours dedicated to the study of parasitology in the BSc Biomedical Science (BMS) programme in 2016/17, which has been translated in a significant increase in student satisfaction as described in Peña-Fernández et al. (2017) [3].

The development of the on-line package, named DMU e-Parasitology, is being carried out by our innovative teaching group in collaboration with different EU Universities including De Montfort University and the Spanish Universities of San Pablo CEU (Madrid) and Miguel Hernández (Elche), in conjunction with clinicians and practising Biomedical Scientists from the UK National Health Service. This novel DMU e-Parasitology [1] package will be publicly available on the DMU website here http://parasitology.dmu.ac.uk/ in 2018. Its development started in 2016 and it is being created for undergraduates and postgraduates studying any human health science programme, so different degrees of difficulty are being considered and targeted. Despite being under development, we have published a comprehensive description of the structure of this novel package in Peña-Fernández et al. (2017) [11]. Briefly, three major modules or sections can be found in the package as follows:

- A theoretical module with e-learning units to study major human parasites including protozoa, fungi, helminths and arthropods. To facilitate their study, we have distributed the helminth parasites according to the three common taxa, i.e. trematodes, cestodes and nematodes. This

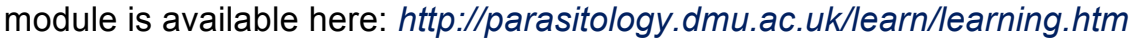

- A virtual laboratory module with engaging and interactive units about different techniques which are relevant for the study of parasitic human diseases, which is available here: http://parasitology.dmu.ac.uk/learn/laboratory.htm

- A virtual microscope with a real slide collection of clinical samples of human parasites. Ordinary micrographs or photographs are limited to a preselected area and magnification but the virtual microscopy will enable viewing of any part of a specimen at any magnification and, therefore, students will be able to identify morphologically the parasite in different clinical samples. Publicly accessible here: http://parasitology.dmu.ac.uk/learn/microscope.htm

\section{METHODOLOGY}

Our teaching team is currently developing a fourth module or section that will present a series of virtual case studies in medical parasitology for promoting active learning and increasing engagement. The virtual case studies are being created following the methodology developed for introducing minicase studies in Medical Microbiology lectures in the BSc Biomedical Science programme at DMU in 2016/17. As described previously [2-3], we developed a series of mini-case studies based on those designed by the Laboratory Identification of Parasitic Diseases (DPDx) of the Centers for Disease Control and Prevention (CDC, USA) [4] and final year BMS students were requested to complete them during the different lectures in a very short period of time. To do this, students were provided with different slides collected from the DPDx in conjunction with a short medical history during the lectures. By peer group interaction, students provided a possible "diagnosis" for each mini-case study based on 
the clinical features presented and microscopic slides provided. Students needed to reflect on their knowledge and from the information provided during the lectures and quickly search for information through web-enabled mobiles, laptops or tablets to propose possible diagnoses. This pedagogic strategy, i.e. the introduction of mini-case studies during lectures, has been shown to be effective in facilitating the acquisition of transversal competences including clinical skills.

In contrast, the virtual case studies for DMU e-Parasitology will be highly interactive and students will need to use the different resources of this package, including the virtual microscope, to resolve them. Moreover, these case studies will be longer and will present different questions that the user will be able to answer depending on their clinical and parasitology skills. Between the many advantages of a virtual microscope described in the literature [12], including remote access to slides of high clinical quality for all users in virtually any environment, this technological resource could facilitate the acquisition of problem-solving skills and hence the rationale of using it to resolve the case studies in DMU e-Parasitology. Thus, Ahmed et al. (2016) [13] have found that skilled parasitologists can reach similar diagnostic accuracy when using virtual microscopes.

\subsection{Development of the model-case study}

Our teaching group has developed the first virtual case study, which is available here: http://parasitology.dmu.ac.uk/learn/case_studies/cs1/story_htm/5.htm/ [5] (Figure 1). This first case study is related with human pathogenic amoebas that can affect HIV positive patients, particularly Entamoeba histolytica and Acanthamoeba spp. that have been described as emerging infectious pathogens by the National Institute of Allergy and Infectious Diseases (NIAID [14]). E. histolytica has been increasingly recognised among men who have sex with men, being a particular risk those with HIV infection [15]. E. histolytica can lead to invasive amoebiasis and has been related with approximately 40,000 to 74,000 deaths/year in the world, being present in non-develop and developed countries [16]. On the other hand, Acanthamoeba spp. cause chronic granulomatous amoebic encephalitis affecting mostly immunocompromised people, including those with HIV [17].



Figure 1. Overview of the main page of the first clinical case study in the DMU e-Parasitology (Image courtesy of DMU; Peña-Fernández et al., 2017 [5]). Available at: http://parasitology.dmu.ac.uk/learn/case_studies/cs1/story_html5.html

The virtual case study was developed using the same software used to develop the package, i.e. Articulate 360 software. The case study consists of a series of highly interactive and visually engaging slides which the user (students) can navigate through, meanwhile answering and completing different types of tests/quizzes and exercises. These tests are formulated in different styles to increase engagement and reasoning such as true/false, multiple choice, ordering, fill-in-the-blank, matching statement, etc., and present different degrees of difficulty so the user is challenged throughout its completion and interest is maintained. To introduce the case study to the user, a short medical history is presented in the first slide. Briefly, the medical history for this first case study presents an HIV positive male university student severely affected by bloody diarrhoea, malaise and fever; and a series of clinical slides in which trophozoites of Entamoeba histolytica and Acanthamoeba spp. can be observed.

Finally, some questions related to the identification of the pathogens involved in this study in virtual clinical slides that are embedded within the case study to enhance engagement. Users/students will 
need to use the virtual microscope so they can morphologically identify the parasite(s) involved (Figure 2). Real clinical glass slides and culture images provided by the DMU e-Parasitology team have been appropriately digitised and uploaded onto the case studies and/or the virtual library in the virtual microscope module. Additionally, images from the DPDx library will be used to enhance the learning of the user. A description of the virtual microscope can be found in Peña-Fernández et al., (2018) [18] published in this proceedings publication.
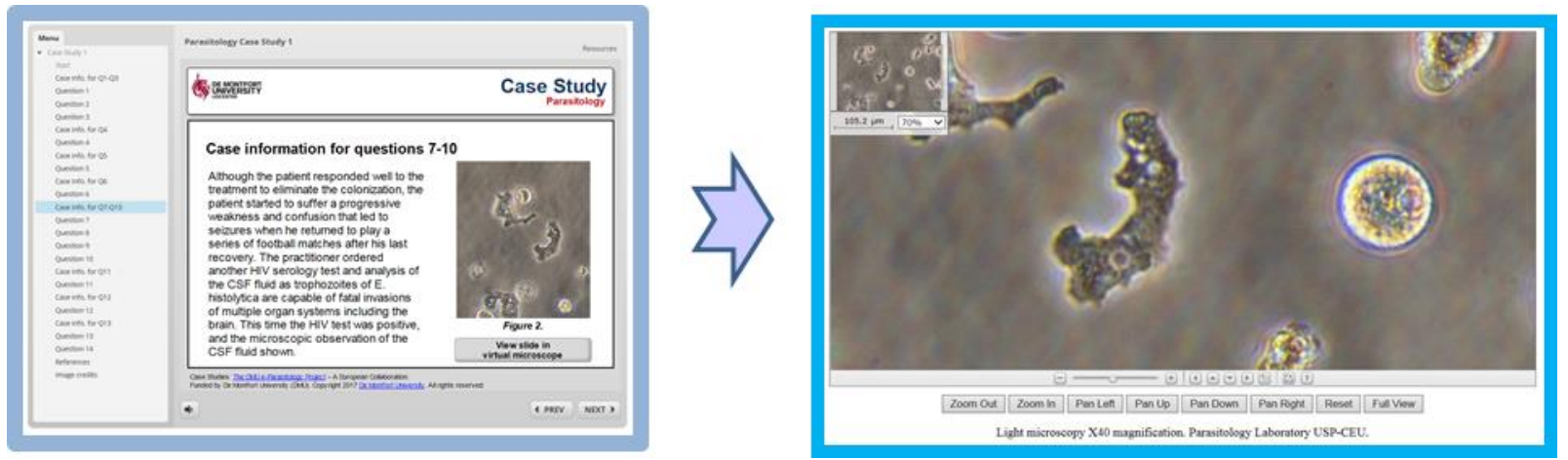

Figure 2. Overview of the first virtual case study for the DMU e-Parasitology in which the applicability of the virtual microscope is shown (Image courtesy of DMU; Peña-Fernández et al., 2017 [5]). Available at: http://parasitology.dmu.ac.uk/learn/case_studies/cs1/story_html5.html

\section{RESULTS}

Students enrolled in the Medical Microbiology module in 2017/18 $(n=193)$ have answered the amoebas case study during small workshops delivered to groups of $27 / 28$ students during November 2017. Students completed the case study in mini-groups of 2 or 3 students each in an hour long workshop session. To facilitate their work and due to the short time of the session, students used two computer screens so they could navigate in the DMU e-Parasitology package, meanwhile the case study was accessible through another screen. Students were debriefed about parasitology in a short 5 minutes introduction at the beginning of the session as they only study parasitology in their first year and later in this final year module of Medical Microbiology.

Comprehensive student feedback is being collected to improve this case study, as it will be used as a model to complete this section of the DMU e-Parasitology. The questionnaire was designed based on previous successful experiences by our team and ethical approval was provided by the Research Ethics Committee at DMU (Ref. 1851; $8^{\text {th }}$ December 2016).

Although our results should be considered as preliminary and a comprehensive analysis of the feedback-questionnaires completed so far is needed, the virtual clinical case study was overwhelmingly welcomed as evidenced by their favourable evaluation. Thus, $100 \%$ students highlighted that the overall design was appropriate and engaging; $80 \%$ reported that the case study was clear; and $100 \%$ gained appropriate knowledge on pathology, prevention and treatment. Several students pointed out that what the most enjoyed was the interactivity and accessibility of the package. Some students indicated that the case study helped them with the study and understanding of the module Medical Microbiology and to test their knowledge.

\section{CONCLUSIONS}

Although a comprehensive evaluation of student performance and feedback provided will be needed to determine whether the clinical case study developed will be successful in teaching some parasitological skills to future biomedical science students or not, we highlight the following outcomes:

1 The virtual case study and the DMU e-Parasitology are interactive and seem to promote students self-learning and interest in learning medical parasitology.

2 Students have gained some medical parasitology knowledge particularly related to pathology, prevention and treatment for the pathogens considered. Moreover, students were able to morphologically determine these pathogens using the virtual microscope. 
3 The virtual case study was shown to be effective to facilitate the acquisition of different transversal competences including critical thinking and reflection, research skills, communication and team work, etc. These competences are necessary for future biomedical scientists.

\section{ACKNOWLEDGEMENTS}

The authors would like to express their sincere appreciation to Jonathan Coope and Maxine Armstrong (DMU) for work on development of DMU e-Parasitology and to USP-CEU Parasitology laboratory for providing high-quality images of parasites in different clinical and culture samples. Finally, we would like to thank the Teaching Innovation Project Fund at De Montfort University (scheme 2015-16) to fund this project to Dr. Peña-Fernández.

\section{REFERENCES}

[1] Peña-Fernández A. DMU e-Parasitology. Available at: http://parasitology.dmu.ac.uk/[accessed 25/01/2018]

[2] Peña-Fernández A., del Águila C., Fenoy S., Magnet A., Izquierdo F., Evans MD., Lobo-Bedmar MC., Peña MA. Applicability of monthly CDC case studies to improve reflection in biomedical science students. ASM Microbe 2017. New Orleans, US, 1-5 June 2017.

[3] Peña-Fernández A., loannou M., Lobo-Bedmar MC., Fenoy S. Curriculum modifications for teaching parasitology and infectious diseases in a Biomedical Science degree. ICERI2017 Proceedings; 1593-1598. ISBN: 978-84-697-6957-7.

[4] CDC (Centres for Disease Control and Prevention). Laboratory Identification of Parasitic Diseases of Public Health Concern (DPDx); Monthly Case Studies 2017. Available at: https://www.cdc.gov/dpdx/monthlyCaseStudies/2017/index.html [accessed 25/01/2018]

[5] Peña-Fernández A, Magnet A., Fenoy S, M.A. Peña, Potiwat N, del Águila C. Case study 1 DMU e-Parasitology. Available at:

http://parasitology.dmu.ac.uk/learn/case_studies/cs1/story_htm/5.html [Accessed 21/01/2018]

[6] Bruschi F. How parasitology is taught in medical faculties in Europe? Parasitology, lost? Parasitol Res 2009; 105(6):1759-62.

[7] Peng HJ, Zhang C, Wang CM, Chen XG. Current status and challenge of Human Parasitology teaching in China. Pathog Glob Health 2012; 106(7):386-90.

[8] Acholonu AD. Trends in teaching parasitology: the American situation. Trends Parasitol 2003; 19:6-9.

[9] Cacciò SM. and Chalmers RM. Human cryptosporidiosis in Europe. Clin Microbiol Infect 2016; 22(6):471-80.

[10] Hotez PJ. Southern Europe's Coming Plagues: Vector-Borne Neglected Tropical Diseases. PLoS Negl Trop Dis 2016; 10(6):e0004243.

[11] Peña-Fernández A., Ollero MD., Fenoy S., Magnet A., Izquierdo F., Peña MÁ., Bornay F., Acosta L., Parker LA., Sgamma T., Del Águila C. Creating a model module for the novel resource DMU e-Parasitology. ICERI2017 Proceedings; 1599-1604. ISBN: 978-84-697-6957-7.

[12] Saco A, Bombi JA, Garcia A, Ramírez J, Ordi J. Current Status of Whole-Slide Imaging in Education. Pathobiology 2016; 83(2-3):79-88.

[13] Ahmed L, Seal LH, Ainley C, De la Salle B, Brereton M, Hyde K, Burthem J, Gilmore WS. WebBased Virtual Microscopy of Digitized Blood Slides for Malaria Diagnosis: An Effective Tool for Skills Assessment in Different Countries and Environments. J Med Internet Res 2016; 18(8):e213.

[14] National Institute of Allergy and Infectious Diseases. NIAID Emerging Infectious

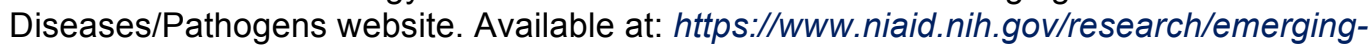
infectious-diseases-pathogens [Accessed 14/01/2018] 
[15] Lo YC, Ji DD, Hung CC. Prevalent and incident HIV diagnoses among Entamoeba histolyticainfected adult males: a changing epidemiology associated with sexual transmission--Taiwan, 2006-2013. PLoS Negl Trop Dis. 2014; 8(10):e3222.

[16] Yanagawa Y, Nagata N, Watanabe K, Tsukada K, Teruya K, Kikuchi Y, Gatanaga H, Akiyama J, Uemura N, Oka S. Increases in Entamoeba histolytica antibody-positive rates in human immunodeficiency virus-infected and noninfected patients in Japan: A 10-year hospital-based study of 3,514 patients. Am J Trop Med Hyg 2016; 95(3):604-9.

[17] Pietrucha-Dilanchian P, Chan JC, Castellano-Sanchez A, Hirzel A, Laowansiri P, Tuda C, Visvesvara GS, Qvarnstrom Y, Ratzan KR. Balamuthia mandrillaris and Acanthamoeba amebic encephalitis with neurotoxoplasmosis coinfection in a patient with advanced HIV infection. J Clin Microbiol 2012; 50(3):1128-31.

[18] Peña-Fernández A., Fenoy S., Halliwell R., Izquierdo F., Magnet A., Hurtado C., Bornay F., Acosta L., Ollero MD., Armstrong M., Evans MD., del Águila C. Development of a virtual library of clinical samples for medical parasitology diagnosis. INTED Proceedings 2018; in press. 